\title{
Evidence of interpopulation variation in the germination of Eryngium maritimum L. (Apiaceae)
}

\author{
I. Cortés-Fernández $($ ) M. D. Cerrato - A. Ribas-Serra • C. Cardona • \\ C. González • L. Gil
}

Received: 18 April 2021 / Accepted: 22 July 2021

(C) The Author(s) 2021, corrected publication 2021

\begin{abstract}
Germination is considered as one of the most crucial steps in a plant's lifetime. The germination of Eryngium maritimum, a dune species located across all European coasts, has been extensively analysed in Northern populations, where it is considered a locally endangered species. However, less attention has been given to southern populations, where the knowledge about the germination of the species is very limited. The main objective of the present study was to analyse the effect of cold stratification in one Mediterranean and one Atlantic population of the species, as well as to compare the potential variation of seed dormancy among a
\end{abstract}

Communicated by Philip Ladd.

Supplementary Information The online version contains supplementary material available at https://doi.org/10.1007/ s11258-021-01164-y.

I. Cortés-Fernández $(\square) \cdot$ M. D. Cerrato .

A. Ribas-Serra · L. Gil

Interdisciplinary Ecology Group, Universidad de las Islas

Baleares, Carretera de Valldemossa,

07122 Palma de Mallorca, Spain

e-mail: ivancf1995@hotmail.com

M. D. Cerrato

e-mail: marcellocerrato@hotmail.com

A. Ribas-Serra

e-mail: arnauribasserra@gmail.com

L. Gil

e-mail: lorenzo.gil@uib.es latitudinal gradient in European populations based on current literature. Seeds collected from Mallorca (Mediterranean, Spain) and Asturias (Atlantic, Spain) were germinated at different temperatures and cold stratification periods ranging from 4 to 20 weeks. These results were merged with the results of previous studies to test the potential effect of latitude and climatic variables in germination. Although the optimal incubation temperature was $10{ }^{\circ} \mathrm{C}$, the highest final germination percentages (up to 96\%) was obtained in both populations combining specific cold stratification periods $\left(5^{\circ} \mathrm{C}\right)$ and constant incubation temperatures $\left(15-20{ }^{\circ} \mathrm{C}\right)$. Atlantic seeds needed longer cold stratification times to reach high germination percentages compared with Mediterranean seeds. Apart from the stratification response, significant differences in viability and in germination were observed between the Atlantic and the Mediterranean

\footnotetext{
C. Cardona

Centre Forestal de les Illes Balears, Institut Balear de la Natura, Gremi Corredors, 10 (Pol. Son Rossinyol),

Palma de Mallorca, Spain

e-mail: aigolob@hotmail.com

C. González

Departamento de Biología de Organismos y Sistemas (Área de Botánica), Universidad de Oviedo, Asturias, Spain

e-mail: gonzaleztclaudia@uniovi.es
} 
populations. Considering data from previous studies in the analysis, the results suggest that there is a potential effect of latitude in the ecological germination requirements, by which the higher the latitude, the longer the cold stratification period required to germinate, with a correlation with the mean annual temperature. These results suggests that two factors, modulation of dormancy relating to adaptative or maternal effects and viability, govern the germination of the species.

Keywords Dormancy - Eryngium maritimum . Germination $\cdot$ Seeds $\cdot$ Cold Stratification

\section{Introduction}

Coastal dune systems are considered one of the most endangered habitats, threatened by several natural and anthropogenic factors, such as sea-level rise, flooding, human trampling and infrastructures (Ciccarelli 2014; Pinna et al. 2015; Gigante et al. 2018). In this context, specific studies that focus on the species that inhabit these areas are extremely important to ensure habitat health (Vallés and Cambrollé 2013).

Eryngium maritimum (L.) is a species from the Apiaceae family that inhabits coastal areas of the Atlantic shores of Europe, including the British islands, the west and east Mediterranean coasts, and more sparingly the Black and Azov Sea coasts (Isermann and Rooney 2014). E. maritimum grows on sandy soils, being present in dune systems where it occurs in several communities mainly in white dunes (shifting coastal dunes), even though it can also be found in grey dunes and occasionally in other coastal or near-dune systems communities (Isermann and Rooney 2014). In the Mediterranean dunes, it develops in the Ammophiletalia phytosociological class, being mainly established in the embryonic and white dunes (Embryonic shifting dunes, Habitat 2110, EUNIS). Clausing et al. (2000) identified two different genetic clusters, the Atlantic and the Mediterranean, because of the Quaternary Würm glacial. As a result of the distribution of ice cover, permafrost and sea surface temperatures in that period, the distribution area of the species must have been dramatically reduced in West, Central and North Europe, while in the Western Mediterranean, temperatures might have been appropriate for the populations survivorship. The conservation status of E. maritimum has been extensively discussed and reviewed for northern European populations, where it is considered a locally endangered species due to habitat loss and potential pollination issues (Maarel and Maarel-Versluys 1996; Aviziene et al. 2008). However, Mediterranean stands have been given less specific attention.

Germination is considered as one of the most crucial phases in a plant's lifetime and also as the bottleneck for plant species' successful establishment (Baskin and Baskin 2014; Del Vecchio et al. 2020). To ensure that it is carried out in the optimal season, many species develop specific germination strategies entailing different types of dormancy. Seed dormancy is considered one of the main factors determining the adaptive value of germination, thereby ensuring initiation of the next generation (Fenner and Thompson 2005; Donohue et al. 2010; Willis et al. 2014). Apart from genetic origin, the level of primary dormancy in seeds may be determined by other factors, such as maternal environment during maturation, age of the mother plant during maturation and position of the seeds on the plant (Andersson and Milberg 1998; Fenner and Thompson 2005). Seed dormancy and germination are complex traits of spermatophytes that are influenced by many genes and environmental factors (Finch-Savage and Leubner-Metzger 2006; Donohue et al. 2010) both in the long term (through ecotypes or clines) and in the short term (through the influence of the seed maturation environment) (Fernández-Pascual et al. 2013).

Many species in the Apiaceae are reported to exhibit morphological dormancy (MD) or morphophysiological dormancy (MPD) (Finch-Savage and Leubner-Metzger 2006; Baskin and Baskin 2014), including the Genus Eryngium (Wolkis et al. 2020). In MPD, the seed coat is water permeable, embryos are undeveloped and also have a physiological inhibiting mechanism that requires an ecological signal to elicit germination (i.e. physiological dormancy; PD; Baskin and Baskin 2014). In the case of E. maritimum, Necajeva \& Ievinsh (2013) reported a morphophysiological dormancy, in which the embryo is not fully formed when the seed is dispersed, obtaining higher germination percentages with cold stratification treatments of $5{ }^{\circ} \mathrm{C}$. This study, carried out with populations of the North of Europe, has shown that cold stratification treatments increase germination up to $90 \%$ after 
16 weeks of cold. However, it has also been reported that cold stratification periods longer than 14 weeks can produce negative effects (Walmsley and Davy 1997). Moreover, Necajeva \& Ievinsh also found that the cold stratification treatment could be substituted by addition of gibberellic acid. Optimal temperatures for germination have been reported with alternating temperatures ranging from $10{ }^{\circ} \mathrm{C}$ to $20{ }^{\circ} \mathrm{C}$ (Walmsley and Davy 1997), increasing embryo development at higher incubation temperatures (Necajeva \& Ievinsh, 2013). However, there is a lack of studies analysing the germination of E. maritimum populations of different latitudes, which could be critical to understand the potential capacity of modulation of MPD of the species.

The main aim of this study is to analyse the germination of E. maritimum in one Atlantic and one Mediterranean population, in order to evaluate the potential differences between populations. The main hypothesis of the present study is that the temperature differences between one Mediterranean and one Atlantic Spanish population of E. maritimum will have a strong impact on germination, the required length of cold stratification increasing at higher latitudes. We also aim to analyse if, considering previous studies carried out with the species, there is a relationship between latitude and the length of the cold stratification to break PD in E. maritimum.

\section{Material and methods}

Seed collection

Fruits were collected in Son Serra de Marina (3.237619/39.731218, WGS84, EPSG: 4326), a dune system located in the northern area of Mallorca (hereafter Mediterranean population), and in Playa de Xagó (- 5.918455 / 43.604510, WGS84, EPSG: 4326), in Gozón, Asturias (hereafter Atlantic population), both representing two different climatic profiles occurring in Spain coasts (Fig. 1). Only seeds from the central capitulum of the E. maritimum inflorescence were collected, in order to avoid potential inter-whorl variability. Two thousand seeds were collected from approximately fifty random individuals during September 2018 (Mediterranean population) for the incubation experiment and September 2019 (Atlantic and Mediterranean populations) for the cold stratification experiment. Controls were compared between both years to avoid the possible effect of interannual variation. Seeds were maintained at $23{ }^{\circ} \mathrm{C}$ and $60 \%$ of relative humidity until pre-germination treatments for 60 days when subsequent germination tests were carried out.

\section{General germination procedure}

The experiments were carried out in the University of the Balearic Islands, Spain. In all trials, seeds were sown in Petri dishes, to avoid desiccation, with paper filters moistened in distilled water, and then incubated at constant temperatures in dark conditions, as Carta et al. (2017) proved that photoinhibition in E. maritimum is negligible. Each trial was conducted using 4 replicates of 25 seeds (total of 100 per trial), which were assessed every two days till a maximum of 90 days since sowing per trial. Seeds were considered germinated when radicle protrusion was visible, and a cut test was assessed on the ungerminated seeds (Baskin and Baskin 2014), considering non-germinated seeds with an embryo as viable seeds and without it as unviable seeds.

In all trials, several germination parameters were calculated as proposed by Aravind et al. (2019). Germination Speed (percentage of germinated seeds per day), final germination percentage, days to reach first and last germination, synchrony of germination and germination uncertainty were calculated as indicated by Dastanpoor et al. (2013).

Optimal incubation temperature

As a pre-step before collecting Atlantic seeds, a first trial was conducted to establish the optimal incubation temperature of Mediterranean seeds in 2018. So, seeds were incubated at $5,10,14,18,20$ and $23{ }^{\circ} \mathrm{C}$ in dark conditions for 90 days, as established in the general germination procedure.

\section{Effect of cold stratification}

A second trial was conducted with seeds from both populations collected in 2019 , in which seeds were incubated at $6,8,10,12$ and 14 weeks of cold stratification at $5{ }^{\circ} \mathrm{C}$ in both populations. Seeds were germinated at constant 15 and $20{ }^{\circ} \mathrm{C}$ in the dark. While carrying out the experiment, considering the low 

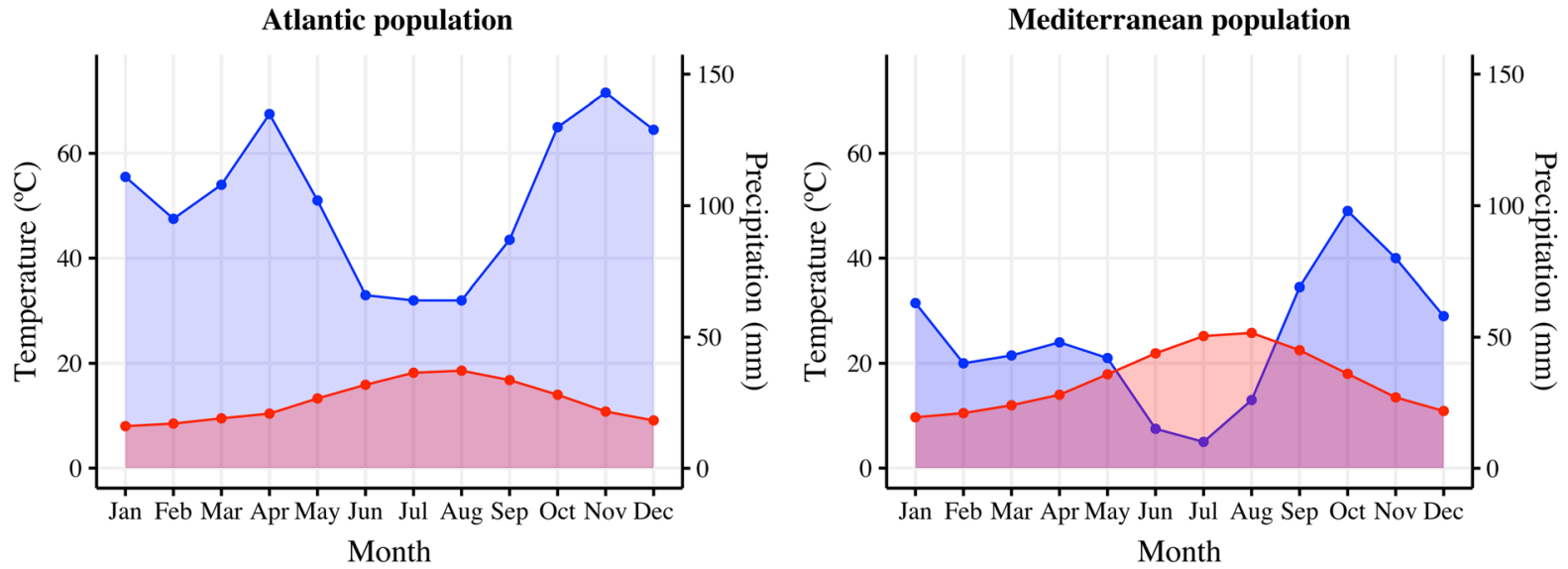

Fig. 1 Ombrothermic diagram of the study sites. Mean precipitation is plotted in blue, while the mean temperature is plotted in red. Data: AEMET 2019

germination percentages of Atlantic seeds (see Results), a surplus of Atlantic seeds (not available in the Mediterranean population) was incubated after 16, 18 and 20 weeks of cold stratification at $5{ }^{\circ} \mathrm{C}$.

\section{Latitudinal variation}

The existing literature regarding germination of $E$. maritimum was gathered to make further analysis, considering the temperature of incubation, latitude, longitude, stratification time and final germination percentage of each trial. Environmental data of each population were extracted using Worldclim (Fick and Hijmans 2017). To make it possible to compare among studies with different stratification times, final germination was weighed with the number of weeks under cold stratification of each treatment, as follows:

Weighted Germination $=\frac{\text { Final Germination Percentage }}{\text { Cold stratification length }(\text { weeks })}$

\section{Statistical analysis}

Germination parameters were calculated using the package Germinationmetrics (Aravind et al. 2019) in $\mathrm{R}$ software (R. C 2013), using the user interface RStudio (RStudio Team 2020). Descriptive statistics and plots were carried out using the Tidyverse library (Wickham 2019).

In the stratification experiment, cumulative germination in the different treatments was modelled considering the germination temperature and the stratification period as the experimental variables, considered in all analyses as numeric variables. For count response variables (day of the first germination), generalised linear models using the Poisson family (link $\log$ ) and zero-inflated models were used. On the other hand, for percentage data (Final Germination Percentage), logistic Generalised Linear Models with a binomial error distribution were used. In all cases, model selection was carried out according to the Corrected Akaike selection Criterion using AICc (Bozdogan 1987; Parmoon et al. 2015). Model accuracy was evaluated using Q-Q plots and McFadden Pseudo-R2 when possible (Veall and Zimmermann 1996). Significant effects of the experimental variables were evaluated using ANOVA (Rutherford 2011).

Data of the present study were gathered with the final germination percentage results of the existing literature to analyse the potential effects of latitudinal variation on the germination. Final germination was modelled using Beta regression models (Zeileis et al. 2016) considering Latitude, Longitude and environmental data as explanatory variables. Final models were achieved via backwards elimination (log-likelihood ratio test, $\mathrm{P}<0.05$ ) using the lmertest package (Kuznetsova et al. 2015). The effect of explanatory variables on final germination was evaluated using ANOVA (Rutherford 2011). 


\section{Results}

Optimal incubation temperature

No germination was observed in the Mediterranean population seeds at 18,20 and $23{ }^{\circ} \mathrm{C}$. Germination increased from $5{ }^{\circ} \mathrm{C}$ (Mean $(M)=6.67 \%$, Standard Deviation $(\mathrm{SD})=3.34$, Number of samples $(N)=4)$ to $10{ }^{\circ} \mathrm{C} \quad(M=30.04 \%, \quad \mathrm{SD}=6.00, N=4)$ and decreased again before $18{ }^{\circ} \mathrm{C}(M=4.55 \%$, SD $=$ $2.21, N=4)$. The low germination observed prevented other variables from being taken into consideration.

\section{Effect of cold stratification}

The percentage of viability among lots was significantly higher $(p<0.001)$ in the Mediterranean $(M=29.5, \mathrm{SD}=2.02, N=52)$ than in the Atlantic population $(M=15.1, \quad \mathrm{SD}=1.37, \quad N=43) \quad$ but showed no difference between temperatures ( $p=0.177$, Table 1). A final germination percentage of $88.4 \pm 0.21 \%$ was obtained in Mediterranean seeds under 12 weeks of cold stratification at $5{ }^{\circ} \mathrm{C}$, followed by constant incubation at $20{ }^{\circ} \mathrm{C}$, while in Atlantic seeds, the maximum mean germination of $70.22 \pm 0.44 \%$ was observed at an incubation temperature of $15^{\circ} \mathrm{C}$ after 20 weeks of cold stratification. The cold stratification treatment had a significant $(p<0.001)$ effect on final germination in both populations, as well as temperature $(p<0.001)$ and their interaction ( $p$ value $<0.001$, Table 2 ). Mediterranean seeds germinated significantly more than Atlantic seeds for the same stratification time ( $p<0.001$, Fig. 2). In contrast to Mediterranean seeds, Atlantic seeds germinated significantly better at $15{ }^{\circ} \mathrm{C}$ than at $20{ }^{\circ} \mathrm{C}(p<0.01)$.

First and last days of germination, as well as the germination time range, were not explained by the analysed variables (Table 2), although Atlantic seeds germinated a few days later than Mediterranean seeds at the same stratification time (Fig. 3), with no significative differences among treatments. In general, seeds germinated quicker at longer cold stratification times. On the other hand, Mediterranean seeds germinated quicker than Atlantic at the same stratification time. Finally, differences in germination synchrony were observed between regions and temperatures, being higher in Mediterranean than in Atlantic seeds and at $15{ }^{\circ} \mathrm{C}$ than at $20{ }^{\circ} \mathrm{C}$.

\section{Latitudinal variation}

Previous literature data were gathered and merged with our results to analyse potential trends at latitudinal level. Seeds reached higher germination percentages at the same stratification time in southern than in northern populations, suggesting a negative correlation between latitude and germination (Fig. 4). The combination of latitude, longitude and the cold stratification period strongly explained final germination $(p<0.001, \mathrm{R} 2=0.743)$, achieving higher germination percentages as latitude decreases $(p<0.001)$. On the other hand, the coldest temperature of the coldest month and the Annual Mean Temperature explained part of the variability observed on the final germination per week of stratification $(p<0.001, F=39.09, \mathrm{R} 2=0.768)$.

\section{Discussion}

Optimal incubation temperature

The results of the pre-study with the Mediterranean population suggest that the optimal incubation temperature is $10{ }^{\circ} \mathrm{C}$ without a cold stratification treatment. However, when applying cold stratification temperatures, this same population reached higher germination percentages at $20{ }^{\circ} \mathrm{C}$ than at $15{ }^{\circ} \mathrm{C}$. This supports the hypothesis that E. maritimum seeds are physiological (PD) or morphophysiological dormant (MPD), and so they need a trigger, in this case, a cold stratification period to begin germination. Considering that MPD was reported by Necajeva and Ievinsh (2013), it can be suggested that embryos are incompletely developed as morphophysiological dormant seeds at the end of the fruiting period (Wolkis et al. 2020), and so they have to develop during autumn and winter, while they need some high temperatures at spring to begin the germination process (Vandelook et al. 2012). Moreover, seeds from the Atlantic population germinated better at $15{ }^{\circ} \mathrm{C}$, which could be linked with the same hypothesis, and so suggests that the species has been able to adapt its ecological germination requirements to the specific 


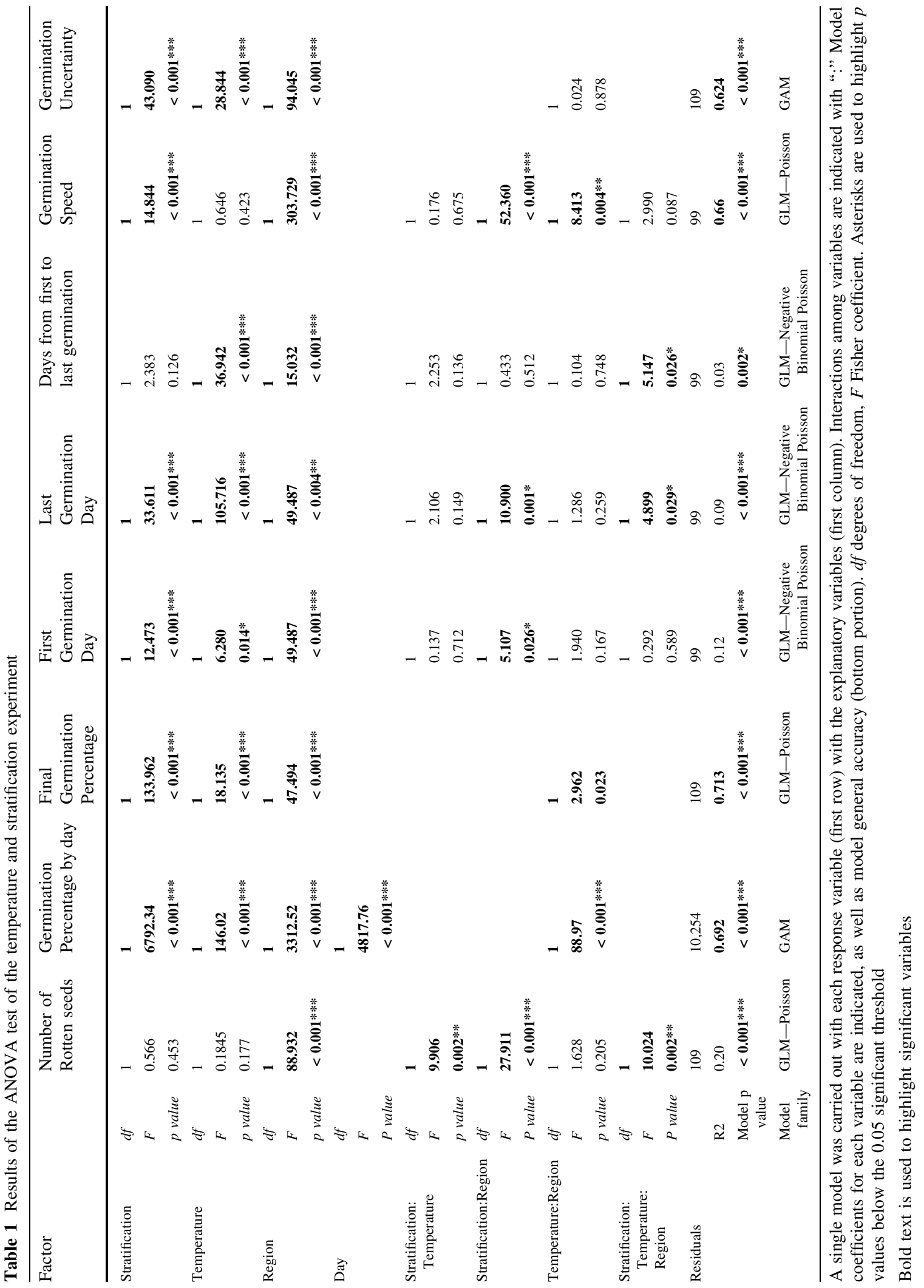


environmental conditions, as occurs in other species (Finch-Savage and Leubner-Metzger 2006).

\section{Effect of cold stratification}

Considering the effect of cold stratification on the germination, the results of the present study show that E. maritimum seeds reach higher germination percentages in the Mediterranean population than in the Atlantic population at shorter stratification periods. So, it can be considered that seeds from the Mediterranean population are less dormant than Atlantic. Compared to Northern European populations, Mediterranean seeds from the present study have reached the highest germination percentages observed in this species (up to 96\%, Fig. 2) (Jankeviciene 1978; Walmsley and Davy 1997; Klavina et al. 2006; Curle et al. 2007; Necajeva \& Ievinsh, 2013) which could be linked to environmental differences among populations (Fig. 1), overall considering climatic interannual variations at the time of seed maturation. However, more populations are required to understand if these differences are related to a latitudinal trend (see Latitudinal variation).

Comparison with previous studies could be biased by the fact that some studies have not made any viability test (Necajeva et al. 2003), which can strongly decrease the maximum germination percentages due to inviable seeds (i.e. empty seeds) (Necajeva et al. 2003). Empty seeds can reach $30 \%$ of the total seed lot (Walmsley and Davy 1997), and sometimes up to $60 \%$ (Aviziene et al. 2008).

The cold stratification treatment proved to have a substantial effect on germination, improving the final germination percentage of both populations. These results are contrary to those obtained in a previous study carried out by Walmsley and Davy (1997) with E. maritimum seeds from Sizewell, United Kingdom, which stated that more than 6 weeks of cold stratification did not increase germination. Similarly, Fernández-Pascual et al. (2017), who analysed the effect of cold stratification requirements of several dune species in the Atlantic seaboard of Northern Spain, proposed that cold stratification did not improved the germination of E. maritimum. However, the optimal stratification period has been suggested to be longer in higher latitudes, like in Asturias or Northern European populations (Necajeva et al. 2003; Klavina et al. 2006).
Latitudinal variation

The results of the present study combined with the results of the previous studies suggest that there is a trend in the germination of this species, in which the higher the latitude and the lower the mean annual temperature, the more weeks of cold stratification are needed to germinate (Fig. 4A, B). Our results suggest that E. maritimum has been able to couple germination dormancy to the specific climatic conditions of each population, preventing seeds in regions with a clear winter season from germinating in summer or autumn, which is a mechanism to decrease the risk of frost damage during the vulnerable seedling stage in winter (Baskin and Baskin 2014; Nikolaeva 2004; Vandelook et al. 2012). This is consistent with the findings of Vandelook et al. (2012), who obtained in a wide analysis of species belonging to the Apiaceae family that germination was mainly related to temperature conditions and altitude. Carta and collaborators (2016) obtained similar results for Hypericum elodes (L.), finding that the effect of cold stratification was weaker in southern populations with no relationship to population genetic differentiation, highlighting that physiological dormancy can be modulated by local climate.

Because of a lack of studies carried out in northern populations applying long cold stratification periods ( $>14$ weeks), in E. maritimum, it is difficult to establish if seeds from northern populations are more dormant or germinate poorly due to other factors such as genetic inbreeding (Isermann and Rooney 2014). In our results with Spanish populations, we have observed a significant interaction between the stratification length and the region, supporting the hypothesis that dormancy increases at higher latitudes. Differences among populations at a latitudinal gradient could also be attributed to genetical variations, as suggested by Clausing and collaborators (2000). Considering these results, populations at the same latitude but influenced by different seas could germinate at different rates, which could explain some observed irregularities in the latitudinal trend. This hypothesis is consistent with our findings, considering the significant effect of the region when leaving aside the effect of the stratification length, and also the differences in the seed viability of both populations. So, it can be suggested that both factors, differences in dormancy due to maternal or genetic effects and differences in seed viability, govern the observed 


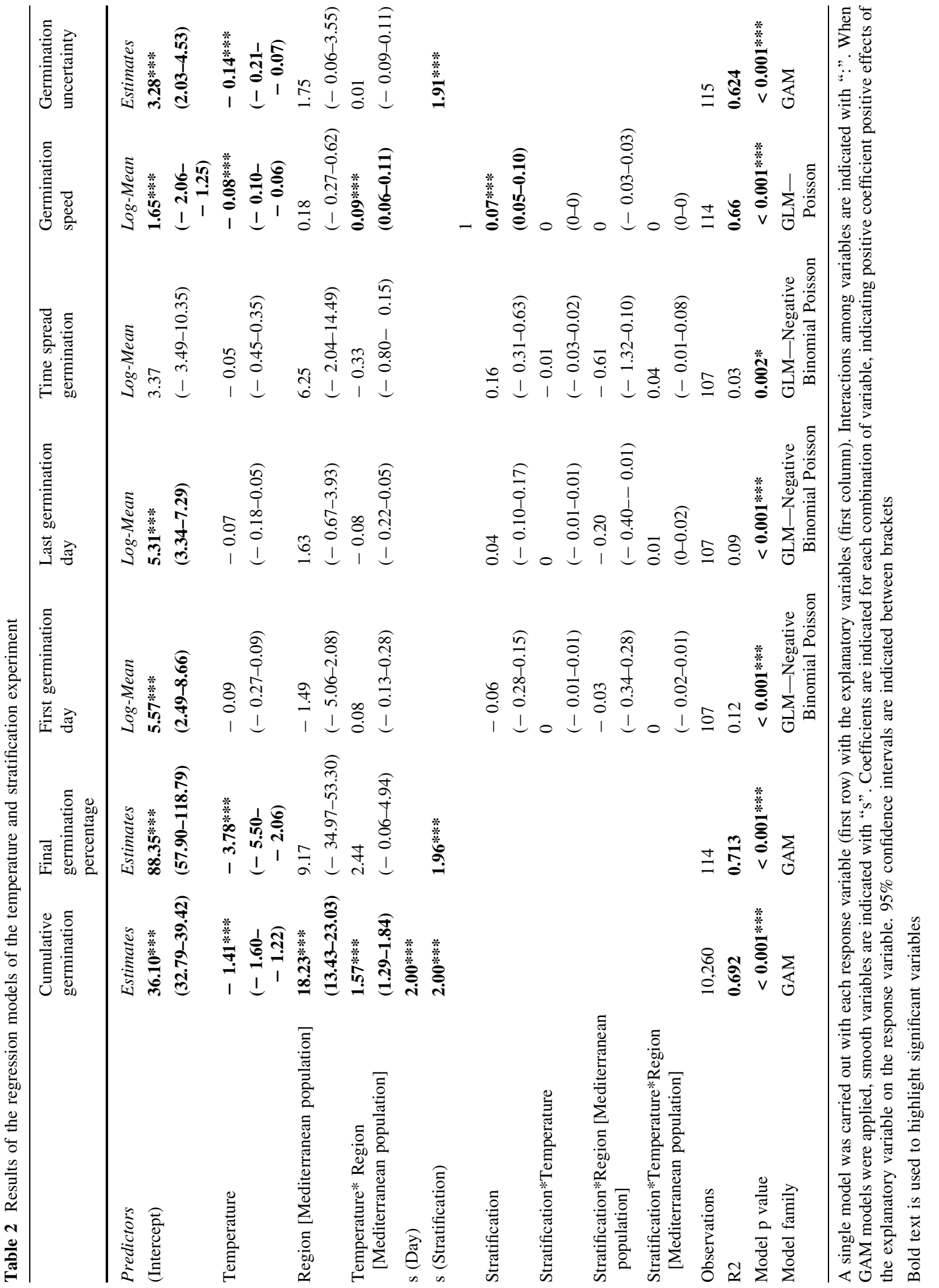




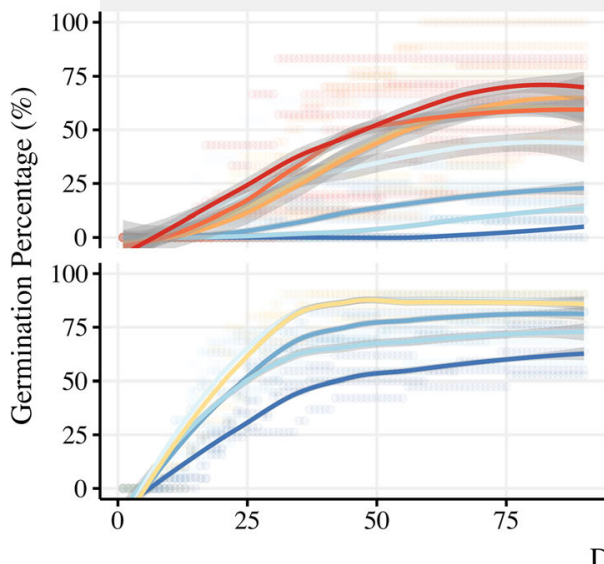

20

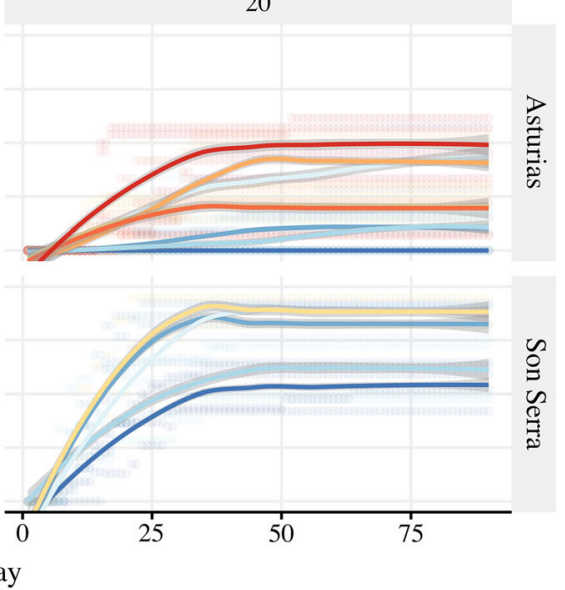

Stratification period (weeks) $=\begin{aligned} & 6 \\ & =8 \\ & -12=14=20\end{aligned}$

Fig. 2 Germination Percentage (left axis) by day (base axis) at two different germination temperatures $\left(15^{\circ} \mathrm{C}\right.$ and $\left.20{ }^{\circ} \mathrm{C}\right)$ and 8 different stratification times (6-20 weeks, blue to red gradient) in the two studied populations
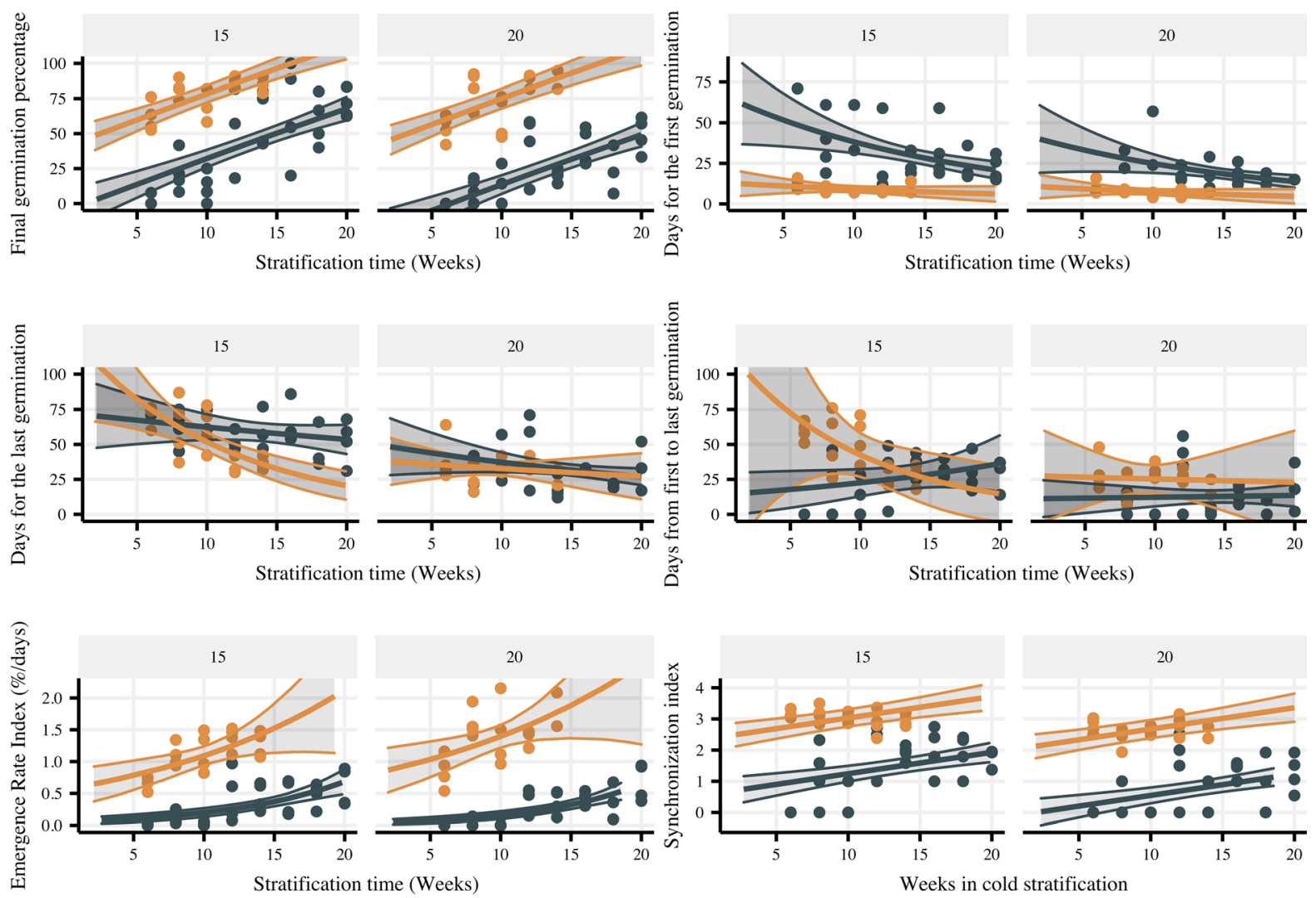

Fig. 3 Observed and predicted data of the germination variables in two different incubation temperatures $\left(15\right.$ and $\left.20{ }^{\circ} \mathrm{C}\right)$ in the two studied populations (Atlantic_-Dark blue; Mediterranean-Orange) 

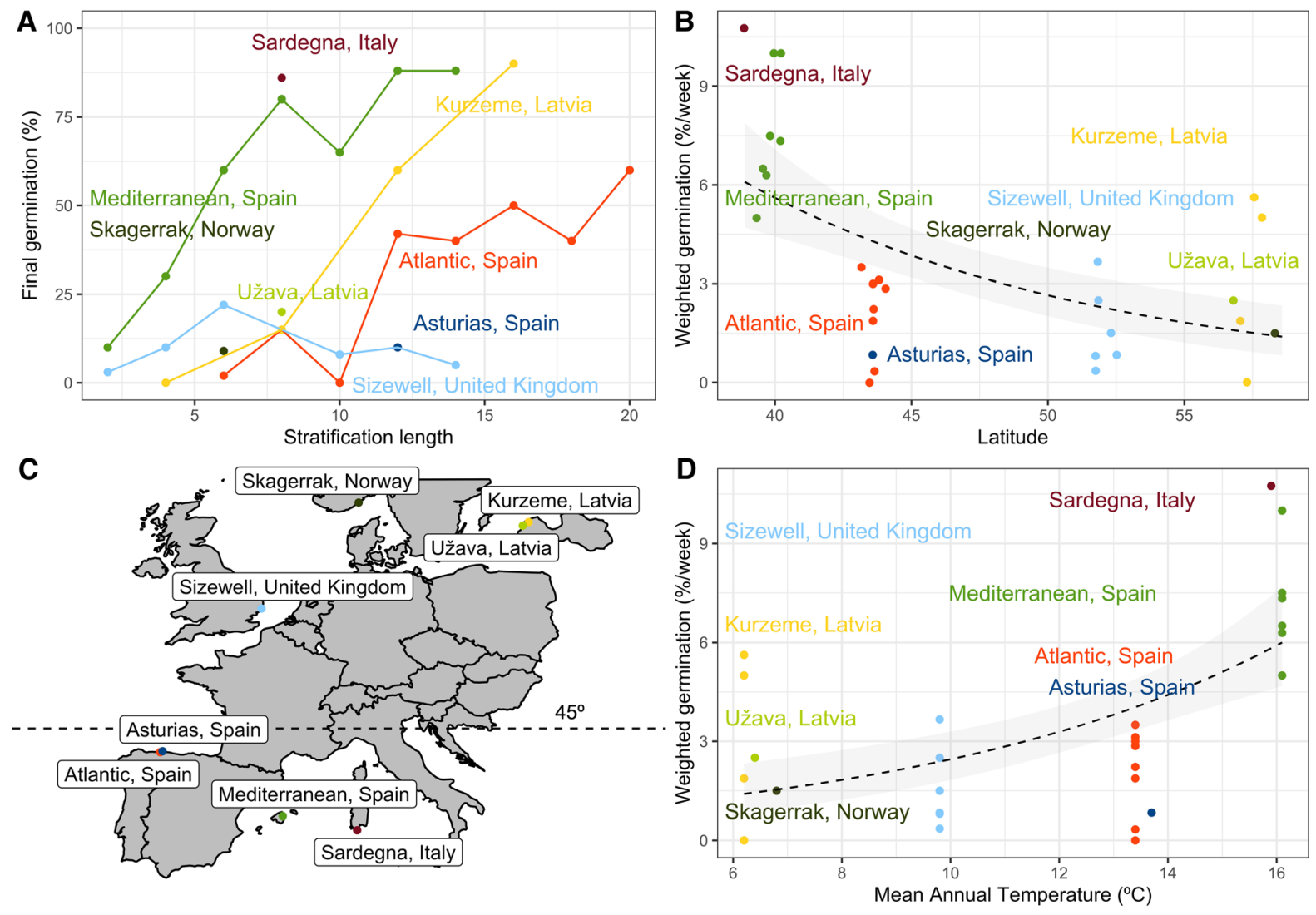

Fig. 4 Meta-analysis considering the potential latitudinal variation of the germination of E. maritimum (More information in Supplementary material-Table S1). In (a), the relation between final germination percentage and the cold stratification length (weeks) is shown. In (b), the weighted germination (final

dynamics of E. maritimum germination along a latitudinal trend across European populations. However, an extensive study considering both factors should be carried out avoiding interannual and methodological variation to prove this trend.

\section{Conclusions}

Germination in E. maritimum is variable depending on the temperature and the stratification length. Cold stratification at $5{ }^{\circ} \mathrm{C}$ increased germination in both populations. Seeds from the Mediterranean population, which are located near the meridional border of its distribution range, need a shorter period of cold temperatures to germinate than those located in Northern populations with colder climates. On the other hand, apart from the effect of stratification, the

germination percentage/stratification length) is plotted against latitude. $\mathbf{c}$ represents the analysed populations, emphasising the analysis below and above the $45^{\circ} \mathrm{C}$ latitude limit. $\mathbf{d}$ analyses the relationship between weighted germination and the annual mean temperature of the populations

Atlantic population has lower viability rates and lower final germination percentages than the Mediterranean population. It can be suggested that two factors, differences in dormancy due to maternal or genetic effects and differences in seed viability, govern the observed dynamics of E. maritimum germination along a latitudinal gradient across European populations.

Acknowledgements We thank Jose Antonio Fernández Prieto from the University of Oviedo for his time and support.

Funding Open Access funding provided thanks to the CRUECSIC agreement with Springer Nature.

Availability of data and material Not applicable.

Code availability Not applicable. 


\section{Declarations}

Conflicts of interest The authors of the present study declare that no conflicts of interest have been present while carrying out this work.

Open Access This article is licensed under a Creative Commons Attribution 4.0 International License, which permits use, sharing, adaptation, distribution and reproduction in any medium or format, as long as you give appropriate credit to the original author(s) and the source, provide a link to the Creative Commons licence, and indicate if changes were made. The images or other third party material in this article are included in the article's Creative Commons licence, unless indicated otherwise in a credit line to the material. If material is not included in the article's Creative Commons licence and your intended use is not permitted by statutory regulation or exceeds the permitted use, you will need to obtain permission directly from the copyright holder. To view a copy of this licence, visit http://creativecommons.org/licenses/by/4.0/.

\section{References}

Andersson L, Milberg P (1998) Variation in seed dormancy among mother plants, populations and years of seed collection. Seed Sci Res 8:29-38

Aravind, J, Vimala, D, Radharani, J, Jacob, S R, Srinivasa, K (2019) The germinationmetrics package: A brief introduction. New Delhi, India: ICAR-National Bureau of Plant Genetic Resources.

Aviziene, D, Pakalnis, R, Sendzikaite, J (2008) Status of redlisted species Eryngium maritimum L. on the Lithuanian coastal dunes. In Environmental Engineering. The 7th International Conference. Vilnius: Gediminas Technical University (pp. 22-28).

Baskin CC, Baskin JM (2014) Seeds: ecology, biogeography, and evolution of dormancy and germination. Elsevier

Bozdogan H (1987) Model selection and Akaike's information criterion (AIC): The general theory and its analytical extensions. Psychometrika 52(3):345-370

Carta A, Skourti E, Mattana E, Vandelook F, Thanos CA (2017) Photoinhibition of seed germination: occurrence, ecology and phylogeny. Seed Sci Res 27(2):131

Ciccarelli D (2014) Mediterranean coastal sand dune vegetation: influence of natural and anthropogenic factors. Environ Manage 54(2):194-204

Curle CM, Stabbetorp OE, Nordal I (2007) Eryngium maritimum, biology of a plant at its northernmost localities. Nord J Bot 24:617-628

Clausing G, Vickers K, Kadereit JW (2000) Historical biogeography in a linear system: genetic variation of Sea Rocket (Cakile maritima) and Sea Holly (Eryngium maritimum) along European coasts. Mol Ecol 9(11):1823-1833

Dastanpoor N, Fahimi H, Shariati M, Davazdahemami S, Hashemi SMM (2013) Effects of hydropriming on seed germination and seedling growth in sage (Salvia officinalis L.). Afr J Biotechnol 12(11):1223-1228

Del Vecchio S, Fantinato E, Roscini M, Acosta AT, Bacchetta G, Buffa G (2020) The germination niche of coastal dune species as related to their occurrence along a sea-inland gradient. J Veg Sci. https://doi.org/10.1111/jvs.12899

Donohue K, de Casas RR, Burghardt L, Kovach K, Willis CG (2010) Germination, post-germination adaptation, and species ecological ranges. Annu Rev Ecol Evol Syst 41:293-319

Elzenga JTM, Bekker RM, Pritchard HW (2019) Maximising the use of native seeds in restoration projects. Plant Biol (stuttg) 21(3):377

Fenner M, Thompson K (2005) The ecology of seeds. Cambridge University Press, Cambridge, UK

Fernández-Pascual E, Jiménez-Alfaro B, Caujapé-Castells J, Jaén-Molina R, Díaz TE (2013) A local dormancy cline is related to the seed maturation environment, population genetic composition and climate. AoB Plants 112(5):937-945

Fernández-Pascual E, Pérez-Arcoiza A, Prieto JA, Díaz TE (2017) Environmental filtering drives the shape and breadth of the seed germination niche in coastal plant communities. AoB Plants 119(7):1169-1177

Fick SE, Hijmans RJ (2017) WorldClim 2: new 1-km spatial resolution climate surfaces for global land areas. Int J Climatol 37(12):4302-4315

Finch-Savage WE, Leubner-Metzger G (2006) Seed dormancy and the control of germination. New Phytol 171:501-523

Gigante D, Acosta ATR, Agrillo E, Armiraglio S, Assini S, Attorre F, Bagella S, Buffa G, Casella L, Giancola C, Giusso del Galdo GP, Marcenò C, Pezzi G, Prisco I, Venanzoni R, Viciani D (2018) Habitat conservation in Italy: the state of the art in the light of the first European red list of terrestrial and freshwater habitats. Rend Fis Acc Linc 29(2):251-265

Jankeviciene R (1978) Retieji Globotini Augalai. Mokslas, Vilnius, Lithuania

Isermann M, Rooney P (2014) Biological flora of the British isles: Eryngium maritimum. J Ecol 102(3):789-821

Klavina D, Gailite A, Ievinsh G (2006) Initial responses of explants from rare and endangered coastal plant species during initiation of tissue culture. Acta Universitatis Latviensis, Biology 710:81-91

Kuznetsova, A, Brockhoff, P B, Christensen, R H B (2015) Package 'Imertest'. R package version, 2(0)

Nikolaeva MG (2004) On criteria to use in studies of seed evolution. Seed Sci Res 14(4):315

Parmoon G, Moosavi SA, Akbari H, Ebadi A (2015) Quantifying cardinal temperatures and thermal time required for germination of Silybum marianum seed. Crop J 3(2):145-151

Pinna MS, Cogoni D, Fenu G, Bacchetta G (2015) The conservation status and anthropogenic impacts assessments of Mediterranean coastal dunes. Estuar Coast Shelf Sci 167:25-31

Porceddu, M., Boi, M. E. \& Bacchetta, G. (2019) Germination data of four Mediterranean species of coastal sand dunes [In Magrini, S. \& Salmeri, C. (eds), Mediterranean plant germination reports - 1]. Fl Medit. 29: 288-292. 2019. https://doi.org/10.7320/FlMedit29.288 
RStudio Team (2020) RStudio: Integrated Development for R. RStudio, PBC, Boston, MA URL http://www.rstudio.com/

Rutherford A (2011) ANOVA and ANCOVA: a GLM approach. John Wiley \& Sons

Team, R C (2013) R: A language and environment for statistical computing

Vallés SM, Cambrollé J (2013) Coastal dune hazards. In: Finkl CW (ed) Coastal Hazards. Springer, Dordrecht, pp 491-510

Van der Maarel E, Van der Maarel-Versluys M (1996) Distribution and conservation status of littoral vascular plant species along the European coasts. J Coast Conserv 2:73-92

Vandelook F, Janssens SB, Probert RJ (2012) Relative embryo length as an adaptation to habitat and life cycle in Apiaceae. New Phytol 195(2):479-487

Veall MR, Zimmermann KF (1996) Pseudo-R2 measures for some common limited dependent variable models. J Econ Surv 10(3):241-259

Walmsley CA, Davy AJ (1997) Germination characteristics of shingle beach species, effects of seed ageing and their implications for vegetation restoration. J Appl Ecol 34:131-142
Wickham H (2016) Ggplot2: Elegant Graphics for Data Analysis. Springer-Verlag, New York

Wickham et al (2019) Welcome to the tidyverse. J Open Source Softw 4(43): 1686. https://doi.org/10.21105/joss.01686

Willis CG, Baskin CC, Baskin JM, Auld JR, Venable DL, Cavender-Bares J, Donohue K, Rubio de Casas R (2014) The evolution of seed dormancy: environmental cues, evolutionary hubs, and diversification of the seed plants. New Phytol 203:300-309

Wolkis D, Blackwell S, Villanueva SKI (2020) Conservation seed physiology of the ciénega endemic, Eryngium sparganophyllum (Apiaceae). Conserv Physiol 8(1):coaa17

Zeileis, A, Cribari-Neto, F, Gruen, B, Kosmidis, I, Simas, A B, Rocha, A V, Zeileis, M A (2016) Package 'betareg'. R package.

Publisher's Note Springer Nature remains neutral with regard to jurisdictional claims in published maps and institutional affiliations. 